\title{
LA TEORÍA DE LAS PARADOJAS COMO ANÁLISIS DEL DISCURSO DE LA IGUALDAD: EL CASO DEL FEMINISMO URUGUAYO (1932-1938) 12
}

\author{
García Álvaro Alonso ${ }^{3}$
}

\begin{abstract}
RESUMEN
Los objetivos de este artículo son básicamente dos. El primero es analizar en clave de las paradojas o contradicciones discursivas algunos argumentos que ofrecieron las feministas uruguayas en sus diversos discursos a favor de los derechos políticos de las mujeres. El otro es tratar de entender estos discursos como limitantes de la participación política de las mujeres, ya que las contradicciones que manejaron en sus argumentos debilitaron la su participación, consolidando un discurso construido y protagonizado por hombres. La hipótesis de este artículo es que los discursos de las mujeres fueron contradictorios, consolidando las relaciones sociales definidas por las jerarquías donde los hombres se consideraban iguales y con derechos, mientras que las mujeres seguían definidas por sus diferencias y por ende eran consideradas inferiores. La metodología utilizada fue definir y estudiar el concepto de "paradojas" aplicado al análisis del discurso político. Para ello nos apoyamos en las historiadoras estadounidenses Joan Wallach Scott y Lynn Hunt, las cuales aportan, en algunos trabajos, la idea de paradoja como anulación de lo que pretendía defender la igualdad entre los individuos. Luego, trataremos del caso uruguayo, con aportes historiográficos y históricos y con opiniones de sus protagonistas. La conclusión principal a la que llegamos es que fueron los hombres que construyeron un discurso hegemónico preconizando la igualdad. Sin embargo, las mujeres fueron las únicas que, más allá de esa igualdad defendida, no podían acceder a sus derechos. Ellas eran considerados seres humanos distintos naturalmente y por ende debían seguir bajo la tutela de los hombres. Cuando en el siglo XX las mujeres lograron el derecho al voto, sus discursos debilitaron su participación efectiva en la política, porque cayeron en las contradicciones que definían una sociedad masculinizada y estructurada en alteridades y jerarquías.
\end{abstract}

Palabras-clave: Mujeres. Política. Paradojas. Discurso. Feminismo.

\section{RESUMO}

Os objetivos deste artigo são essencialmente dois. O primeiro é analisar por meio dos paradoxos ou contradições discursivas alguns argumentos oferecidos pelas feministas uruguaias em seus diversos discursos a favor dos direitos políticos das mulheres. O outro é tentar entender esses discursos como limitantes da participação política das mulheres, já que as contradições que apresentaram em seus argumentos enfraqueceram a sua participação, consolidando um discurso construído e protagonizado por homens. A hipótese deste artigo é a de que os discursos das mulheres foram contraditórios, consolidando relações sociais definidas pelas hierarquias onde os homens eram considerados iguais e com direitos, enquanto as mulheres seguiam definidas por suas diferenças e, portanto, eram consideradas inferiores. A metodologia utilizada foi a de definir e estudar o conceito de "paradoxos" aplicado à análise do discurso político. Para isso, nos apoiamos nas historiadoras estado-unidenses Joan Wallach Scott e Lynn Hunt, que trazem, em alguns trabalhos, a ideia do paradoxo como a anulação do que pretendia defender a igualdade entre os indivíduos. Então, partiremos para o caso do Uruguai, com informações historiográficas e históricas e com a opinião de seus protagonistas. A principal conclusão a que chegamos é a de que foram os homens que construíram um discurso hegemônico defendendo a igualdade. Ainda, as mulheres eram as únicas que, apesar da igualdade defendida, não podiam ter acesso aos seus direitos. Elas eram consideradas seres humanos naturalmente diferentes e, portanto, deviam permanecer sob a tutela dos homens. Quando, no século XX, as mulheres ganharam o direito de votar, seus discursos enfraqueceram sua participação efetiva na política, pois caíram nas contradições que definiam uma sociedade masculinizada e estruturada em alteridades e hierarquias.

Palavras-chave: Mulheres. Política. Paradoxo. Discurso. Feminismo.

\author{
ABSTRACT \\ The objectives of this article are basically two. The first is to analyze some arguments offered by Uruguayan \\ feminists in their various discourses in favor of women's e political rights in the key of paradoxes or discursive

\footnotetext{
${ }^{1}$ DOI: http://dx.doi.org/10.5380/recp.v8i2.50064

${ }^{2}$ Submetido em: 5 de janeiro de 2017. Aprovado em: 13 de julho de 2017.

${ }^{3}$ Profesor de Historia del Instituto de Profesores Artigas (Montevideo) y Maestrando en Historia Social y

Cultural por la Universidad de Montevideo (Montevideo)
} 
contradictions. The other is to try to understand these discourses as limiting the political participation of women, since the contradictions that they handled in their arguments weakened their participation, consolidating a discourse constructed and carried out by men. The hypothesis of this article is that women's discourses were contradictory, consolidating social relations defined by hierarchies where men considered themselves equal and with rights, while women remained defined by their differences and therefore considered inferior. The methodology used was to define and study the concept of "paradoxes" applied to the analysis of political discourse. For this we rely on American historians Joan Wallach Scott and Lynn Hunt, who provide, in some works, the idea of paradox as an annulment of what was intended to defend equality between individuals. Then, we will deal with the Uruguayan case, with historiographical and historical contributions and opinions of its protagonists. The main conclusion we reached is that it was the men who built a hegemonic discourse advocating equality. However, women were the only ones who, beyond that defended equality, could not access their rights. They were considered different human beings naturally and therefore had to remain under the tutelage of men. When in the twentieth century women achieved the right to vote, their speeches weakened their effective participation in politics, because they fell into the contradictions that defined a masculinized society and structured into alterities and hierarchies.

Keywords: women. Politics. Paradoxes. Discourse. Feminism.

\section{LAS PARADOJAS: APORTES TEÓRICOS}

Según el diccionario de la Real Academia Española (PARADOJA, 2017), la paradoja (del latín "paradoxa") se define como "lo contrario a la opinión común": son expresiones que en el lenguaje retórico expresan contradicciones entre sí. La historiadora norteamericana Joan Wallach Scott (2012a, p. 21) dice: "Técnicamente, los lógicos la definen como una proposición irresoluble, que es verdadera y falsa al mismo tiempo. [...] la paradoja es un signo de la capacidad de equilibrar pensamientos y sentimientos complejamente contradictorios". Las paradojas resultan así contraproducentes. Se utilizan para desafiar la ortodoxia del pensamiento dominante, pero al poner en discusión esas categorías del discurso no sustituyen aquellas que quieren negar: "crean una situación que de alguna manera corresponde a la definición técnica de paradoja” (SCOTT, 2012a, p. 21), porque, al no sustituir las diferencias que niegan, las están reafirmando.

Michel Foucault planteó el análisis del discurso como una forma de desentrañar los contextos, límites y correlaciones con otros enunciados que pueden tener vínculos con él. Esa forma de deconstruir ${ }^{4}$ los discursos muestra las diversas aristas de análisis en las cuales puede colocarse un discurso. El lenguaje adquiere así diversas significaciones. Expresa Foucault (2007, p. 45) que "se debe mostrar por qué [una cosa] no podía ser otro de lo que era, en qué excluye a cualquier otro, cómo ocupa, en medio de los demás y en relación con ellos, un lugar

\footnotetext{
${ }^{4}$ El término "deconstrucción”, utilizado por el filósofo francés Jacques Derrida, es entendido como un desarmar la escritura y analizar sus diversos significados. Expresa Derrida (1986, p. 16-17): "La 'racionalidad' [...] que dirige la escritura así ampliada y radicalizada, ya no surge de un logos e inaugura la destrucción, no la demolición sino la des-sedimentación, la des-construcción de todas las significaciones que tienen fuente en este logos".
} 
que ningún otro podría ocupar"5. Las paradojas como recurso analítico del discurso sirven para desentrañar ese logos que está como oculto y que determina formas y significados diferentes. El contexto histórico y las intenciones en que se expresan esos discursos tienen significados específicos.

Joan Wallach Scott ha sido pionera en el desarrollo de esta forma de análisis para la Ilustración francesa. Su tesis radica en que las mujeres que luchaban por sus derechos políticos y por la igualdad respecto a los hombres desde la Revolución francesa lo hacían resaltando sus diferencias — ofrecían así un discurso contradictorio a la hora de reclamar sus derechos políticos y civiles. Scott utiliza el ejemplo de Olympe de Gouges (apud SCOTT, 2012a, p. 20) ${ }^{6}$, quien en 1788 expresaba:

Si voy mas [sic] allá de este asunto, llegaré demasiado lejos y me atraeré la enemistad de los nuevos ricos, quienes, sin reflexionar sobre mis buenas ideas ni apreciar mis buenas intenciones, me condenarán sin piedad como una mujer que sólo tiene paradojas que ofrecer, y no problemas fáciles de resolver.

De Gouges era consciente, explica Scott, de que sus posiciones en torno a los derechos de las mujeres le traerían la enemistad de mucha gente, pero lo peor obstáculo que debería enfrentar era que ella, como mujer, no podía sostener un discurso sin caer en las contradicciones que el mundo masculino imponía.

Los movimientos feministas surgieron como protesta a la exclusión, pero en sus discursos partían de argumentos donde en vez de incluir las mujeres como seres iguales a los hombres, lo hacían resaltando las diferencias entre sí. Esa paradoja es la de "aceptar y rechazar al mismo tiempo la 'diferencia sexual' que quería eliminar” (SCOTT, 2012a, p. 20). Estas contradicciones son propias de una construcción argumentativa que la democracia, como concepto masculino, instaló. Scott complejiza el análisis historiográfico de las mujeres y los movimientos feministas, y reconoce que no son simplemente la historia lineal de mujeres heroínas que lucharon por sus derechos, sino

[...] la historia de mujeres que solo tienen paradojas para ofrecer, no porque [...] su capacidad de razonamiento sea deficiente o su naturaleza fundamentalmente contraria, ni porque el feminismo sea una corriente que aún no ha conseguido plantear bien su teoría y su práctica, sino porque, históricamente, el feminismo occidental ha sido constituido por las prácticas discursivas de la política democrática, que han hecho equivalentes la individualidad y la masculinidad. (SCOTT, 2012a, p. 21).

\footnotetext{
${ }^{6}$ Olympe de Gouges sería la autora, en 1791, de "Los derechos de la mujer y la ciudadana", en plena época de la Revolución francesa.
} 
Esa democracia occidental planteada por hombres es la que ha construido conceptos que sustentan las diferencias. Scott explica que la individualidad como una cualidad abstracta capaz de definir a los seres de una misma especie y diferenciarlos de los demás era, en principio, un concepto universal. Es así que los derechos humanos manejados durante la Francia revolucionaria identificó derechos humanos naturales y universales. Esos derechos universales daban una garantía común a todos: poseer derechos políticos. Entender a los individuos como seres capaces de tener derechos naturales era abstraer de la su definición cualquier configuración material, en tanto no se diferenciaban por la riqueza, la ocupación, el origen social, el nivel cultural. Así mismo, significaba eliminar cualquier signo corporal que los diferenciara entre ellos, como el color de piel y el sexo. Esa abstracción, dice Scott (2012a, p. 23),

[...] posibilitaba plantear una igualdad humana fundamental, un conjunto de rasgos universales, y abría camino para pensar en la igualdad política, social e incluso económica. Si los seres humanos eran fundamentalmente iguales, podían ser concebidos como un solo individuo.

Sin embargo, la categorización de "individuo abstracto" también podía servir para excluir a los que se consideraba que no reunían las características propias de los individuos. En el siglo XIX se planteó que la fisiología podía crear diferencias en ese sentido, de manera que el color de la piel o los órganos reproductivos podrían ser delimitadores de la capacidad humana. Scott (2012a, p. 23) explica que

Los psicólogos utilizaban esas diferencias orgánicas para distinguir entre los que representaban al individuo a través de su razón y su integridad moral (los hombres blancos) y aquellos (otros: las mujeres, e inicialmente también los negros) cuyas llamadas "tendencias naturales" les impedía estar a la altura de ese prototipo.

De esta manera, el "individuo" era el hombre blanco, el cual tenía derechos y era tratado en su individualidad. Las mujeres eran vistas por su alteridad en una condición de inferioridad y lo masculino predominaba en una relación de poder jerarquizada por las cualidades propias y individuales de un ser humano con derechos naturales. Esas diferencias naturales hacían que las mujeres no pudieran actuar libre y individualmente, por eso necesitaban de la tutela de los hombres. El médico Pierre Jean Georges Cabanis (apud SCOTT, 2012a, p. 25) sostenía que 
[...] todos los seres humanos tenían en común una sensibilidad visceral por el sufrimiento de otros y, por consiguiente, la capacidad de moralidad, pero distinguía entre la profunda y deseable sensibilidad de los hombres y los sentimientos efímeros de las mujeres.

La idea de un individuo abstracto que iba en contra de las jerarquías y privilegios creados por los regímenes monárquicos traía, así, argumentos contradictorios para mantener dominios sobre grupos constituidos por sus diferencias. Esta forma de considerar la individualidad sosteniendo la diferencia explica la aplicación de esa idea en la política y la su relación con la cuestión del género. Scott (2012a, p. 25) señala que "la infinita variedad de la diferencia entre yo y el otro quedaba reducida a una cuestión de diferencia sexual: masculinidad equivalía a individualidad, y feminidad a alteridad, en una oposición fija, jerárquica e inmóvil".

La sociedad patriarcal, de la cual los hombres (padres, esposos, hermanos) son el centro, reproduce el modelo de legislador como creador de un orden social. Las mujeres garantizan el orden jerárquico no solo como sometidas a inferioridad de condiciones sino como garantes de la reproducción, función que era propia de su sexo. Durante la Revolución francesa, André Amar (apud SCOTT, 2012a, p. 73) se preguntaba si las mujeres podían tener derechos políticos y ejercer funciones de gobierno. La respuesta a la que llegó fue que no, porque "eso las obligaría a sacrificar los cuidados más importantes a los que la naturaleza las llama. Las funciones privadas a las que están destinadas las mujeres [...] es resultado de las diferencias entre el hombre y la mujer".

De acuerdo con Scott (2012a, p. 215), el feminismo no fue una lucha contra los derechos universales ni los gobiernos republicanos sino uno de sus efectos, producido por afirmaciones contradictorias. El feminismo reivindicó la igualdad con argumentos contradictorios que lo debilitaron en su alcance.

El discurso democrático que se conformó desde la Ilustración hasta el siglo XX miraba exclusivamente a los hombres como los protagonistas de la vida política y de la sociedad. De ahí que las mujeres, cuando comenzaron a buscar argumentos para reivindicar espacios dentro del sistema democrático, partieron de las diferencias que tenían con los hombres y no se igualaron a ellos como seres humanos en sí. Desde la Revolución francesa hasta mediados del siglo XX, la universalidad de derechos estuvo caracterizada por la paradojal evidencia de la exclusión. Una revolución que surgió con el lema — por demás revolucionario — de "Libertad, Igualdad y Fraternidad" consolidó las diferencias entre los sexos. La Declaración de Derechos del Hombre y del Ciudadano de 1789 estableció la idea de 
la igualdad y la libertad entre los hombres, excluyendo de manera directa a las mujeres. Comenzaba de esta manera una larga historia de contradicciones y polémicas entre hombres, pero también entre hombres y mujeres, donde los convencionalismos sociales y culturales generaron más de una incompatibilidad en materia argumentativa.

Lynn Hunt (2009, p. 18) toma la idea de que los derechos humanos se aprobaron con pretensiones de evidencia. Esa presunta evidencia representaba el universalismo que se le pretendían dar a los derechos, es decir, su reconocimiento en todas partes y la idea de que incluía a todos los sectores sociales. Sin embargo, esa pretensión de evidencia implicó paradojas, puesto que si la igualdad de derechos era tan evidente, “¿por qué tuvo que hacerse esta aserción y por qué se hizo solamente en momentos y lugares específicos? ¿Cómo pueden los derechos humanos ser universales si no se reconocen universalmente?" (HUNT, 2009, p. 18). El universalismo fue masculino, creado por hombres, y por eso los discursos y la colocación en determinados lugares correspondió a estos. La intención de la idea del universalismo fue conceder derechos a todos, pero sin que se perdieran las funciones sociales ya asignadas por la naturaleza, lo que además implicaba no perder espacios de poder.

Hunt (2009, p. 26-27) explica que a partir del siglo XVIII se creó "la invención de la autonomía", donde la creencia establecía que todos los "seres humanos normales" eran iguales y capaces de vivir en una moral de autogobierno. La discusión a partir del siglo XVIII se centró en quienes eran esos "individuos normales", ya que se partía de la base de que no todos estaban capacitados para tomar decisiones por sí mismos o no poseían la capacidad de razonar. Los niños, los locos, los sirvientes y los esclavos no poseerían la capacidad de razonar y de ser independientes, pero tal vez (cuando lograran la mayoría de edad, fueran liberados, dejaran de servir o se curaran) pudiesen lograr la individualidad. Las mujeres eran las únicas que no poseían esa capacidad de individualizarse y poder superar sus condiciones de inferioridad. Eran definidas

[...] como inherentemente dependientes de sus padres o sus maridos. Si los defensores de los derechos humanos universales, iguales y naturales excluían de forma automática algunas categorías de personas del ejercicio de esos derechos, ello era debido principalmente a que consideraban que no eran del todo capaces de tener autonomía moral. (HUNT, 2009, p. 26-27).

Para Victoria Camps (2000, p. 11), el discurso feminista ha sido siempre una denuncia contra el individualismo, pero sin proyección real: "un pensamiento en masculino que excluye de hecho a los que no caben en tal paradigma". De esta contradicción es que

\footnotetext{
${ }^{7}$ Según Hunt, este concepto corresponde al filósofo contemporáneo norteamericano Jerome. B. Schneewind.
} 
surge, para Camps, la disputa por el espacio público — reservado para los hombres —, y no por el privado, de dominio femenino. Para la autora, la discusión siempre se centró en el espacio público, mientras que nunca se habló del espacio privado, donde radica el origen de las desigualdades y desde donde derivan las demás. En el siglo XX, las sufragistas pedirán el derecho al voto, pero la mayoría de las mujeres acatarán la idea de que su condición natural las lleva al ámbito del hogar, donde tienen una responsabilidad de formadoras y sostenedoras del orden social. La permanencia en el ámbito doméstico formaría parte de una condición natural que las mujeres debían mantener, pese a los derechos reclamados.

En cuanto a la metodología de análisis aquí adoptada (leer discursos en busca de paradojas),

[...] requiere un tipo de lectura distinto del que los historiadores acostumbran hacer. Estamos habituados a leer buscando el choque de posiciones opuestas [...] pero no las tensiones e incompatibilidades internas [...] de las que esos choques son a la vez síntomas y causa. (HUNT, 2009, p. 35).

Además, leer en clave de paradoja deconstruyendo los discursos "no funciona cómodamente con la narrativa lineal ni con la teleología, dado que tiende a socavar las historias que establecen la verdad o la inevitabilidad de determinadas visiones del mundo, eliminando la mención de conflictos y poder dentro de ellas" (HUNT, 2009, p. 35).

Utilizar a las paradojas como recurso analítico es repensar en parte las distintas teorías acerca del feminismo como movimiento y redefinir las posiciones y posturas de quienes fueron protagonistas en su tiempo de los cambios propuestos. No se trata de restarle importancia al feminismo como movimiento generador de transformaciones, ni quitarle trascendencia a los logros alcanzados por las mujeres en materia de derechos políticos y civiles. Se trata de utilizar una forma digna de analizar discursos que encierran contradicciones conceptuales y que pudieron debilitar el alcance de esas reformas, que, si bien se aprobaron en los hechos, siguen teniendo poco alcance. Pese al tiempo transcurrido desde la aparición del movimiento feminista organizado, hoy se sigue discutiendo la poca representatividad que tienen las mujeres en el sistema político uruguayo.

\section{LAS PARADOJAS EN EL CASO URUGUAYO}

En 2009 el parlamento uruguayo aprobó la Ley n ${ }^{\circ} 18.476$, la cual establece que en las elecciones de primer grado - es decir, para cargos representativos nacionales y 
departamentales - y de segundo grado — para las internas partidarias — deberán incluirse candidatos de ambos sexos por ternas (URUGUAY, 2009). La ley es muy cuestionada no solo por los que dicen que las mujeres deberían ganarse los espacios por méritos propios y no por el imperativo de una ley, sino por aquellos que critican los acuerdos partidarios que violan las cuotas políticas, utilizando corrimientos y mecanismos de suplencias por el cual predominan los hombres a las mujeres. La ley presenta algunas ambigüedades, como la de establecer que de cada tres candidatos deberán incluirse personas de ambos los sexos, sin establecer cuántos hombres y cuántas mujeres. Esto genera que, comúnmente, de tres candidatos haya dos hombres y una mujer, lo que provoca disparidad de números. La ley no parece asegurar la igualdad o el reparto equitativo de candidaturas de ambos sexos, sino simplemente actuar como un paliativo muy flexible frente a una situación que se reconoce como de desigualdad entre hombres y mujeres ${ }^{8}$. Efectivamente, el número de mujeres que actúan en los órganos de representación sigue siendo escaso ${ }^{9}$.

En 2011, la Oficina de Planeamiento y Presupuesto elaboró un estudio sobre la participación política de las mujeres en Uruguay. En el prefacio del documento se expresa: "El ejercicio de la ciudadanía activa por parte de las mujeres es hoy una necesidad impostergable para mejorar la calidad de la democracia”. Más adelante se establece que

\begin{abstract}
Analizar el número relativamente escaso de mujeres electas, que contrasta con el de las mujeres votantes, sugiere que a pesar de la remoción de obstáculos legales, que ha establecido una igualdad potencial para el hombre y la mujer en el desempeño de cargos de elección popular, subsisten fenómenos culturales relacionados con el papel de la mujer en la sociedad que dificultan que la igualdad jurídica se refleje en la práctica. (BRUERA; GONZÁLEZ, 2011, p. 9).
\end{abstract}

Pese a los avances legislativos y a la obtención de derechos políticos, en la actualidad el tema de la participación de la mujer en cargos de representatividad es muy frecuente. Es por esto que la reflexión histórica lleva a rastrear esas limitaciones. Las causas de esa sin duda son múltiples, pero la duda es si en los discursos de las mujeres no se pueden ver precisamente esos fenómenos culturales que actúan como frenos para el ascenso de las mujeres en la igualdad política respecto a los hombres, más allá de la aprobación de las leyes que amparan sus derechos.

\footnotetext{
${ }^{8}$ Para un estudio más completo sobre el tema de la ley de cuotas, ver el trabajo de Johnson et al. (2015)

${ }^{9}$ Recientemente la Cámara de Senadores aprobó un proyecto por el cual los lugares de representación deben ser los mismos para titulares y suplentes, es decir, tanto para los titulares como para los suplentes deberán colocarse personas de ambos sexos. El proyecto tuvo media sanción del Senado.
} 
Las elecciones del 27 de marzo de 1938 fueron las primeras donde las mujeres votaron a nivel nacional ${ }^{10}$. En dicho acto, el triunfo correspondió al General Alfredo Baldomir $^{11}$. La revista Mundo Uruguayo (LA IMPRESIÓN..., 1938, p. 8) publicó varios artículos sobre el histórico acontecimiento, ya que eso "era un aspecto nuevo en las elecciones, cuya fisonomía tradicional se trocaba en una muy diferente, con el solo espectáculo de la mujer votando". Las mujeres, decía el artículo, "han votado con gran naturalidad y ahora están contentas. Se han incorporado sin tropiezo ninguno al ejercicio de la soberanía. ¿Qué más se puede pedir?”. En el su comentario, el artículo desprende una visión frívola del acto eleccionario debido esencialmente a la participación de las mujeres. En la concepción de muchos hombres, la política representaba la imagen de la virilidad, la razón y la fuerza. Las mujeres eran débiles, sensibles y actuaban bajo el influjo del instinto materno. Por eso, "espectáculo", "naturalidad" y "contentas" son expresiones que encierran en el discurso cierto carácter trivial acerca de un acto como el electoral, cuyos resultados influían en el futuro del país. Se desprende una ciudadana que mantendría su feminidad y que se limitaría solo a votar. Ese ejercicio de soberanía implicaba únicamente el acto de votar, y no otras formas de participación. Ese “¿qué más se puede pedir?” es una conclusión definitiva a un reclamo que las mujeres hicieron y que, materializándose en las elecciones, llegaba a su fin. Las mujeres podían votar y nada más; no se abría el espacio para pensar en la su intervención directa.

La misma revista, Mundo Uruguayo, realizó unos días antes de las elecciones de 1938 una compulsa entre algunas mujeres "de activa actuación política en los diferentes partidos existentes” (INFLUIRÁ..., 1938, p. 8). La pregunta formulada fue: “¿Influirá el voto de la mujer en la política del país?” María García Lagos de Hughes, integrante del partido católico Unión Cívica, expresaba:

\begin{abstract}
Creo que la mujer se ha dado cuenta $[\ldots]$ de la responsabilidad que pesa sobre sus hombros. [...] La mujer debe aportar a la política [...] el caudal de su experiencia, de su ternura, de su criterio femenino; ella debe colaborar con el hombre en todo lo que es de su reporte; la defensa del niño, del hogar, de la escuela, la condición de la obrera, en la fábrica y en el taller; el fomento de carreras universitarias, la custodia de la moral y de las costumbres... es decir, en todo aquello que a la mujer conviene y corresponde. (INFLUIRÁ..., 1938, p. 8).
\end{abstract}

\footnotetext{
${ }^{10}$ La primera vez que votaron las mujeres en el Uruguay fue en el plebiscito desarrollado en la localidad de Cerro Chato el 3 de julio de 1927. Véase el artículo del diario El País, A 90 años... (2017). Para ampliar el conocimiento sobre el tema de las elecciones de 1938 en la prensa, ver La mujer... (1938, p. 5), Por primera... marzo (1938, p. 5) y Patrióticamente... (1938, p. 5).

${ }^{11}$ Para ampliar el tema de Baldomir y las elecciones del 27 de marzo de 1938, ver Oddone (1990, p. 169-177). También se puede consultar la investigación de Ana Frega, Mónica Maronna y Yvette Trochón (1987, p. 90 a 99).
} 
Para resaltar la influencia del voto de la mujer, García Lagos parte de la diferencia de esas en relación a los hombres. El voto servía como instrumento en tanto consolidaba las funciones que las mujeres tenían como madres y esposas. Las mujeres mantenían sus condiciones morales y maternales, sin verse alteradas por la condición de ciudadanas.

En otro sentido se expresó Sara Rey Álvarez, fundadora del Partido Independiente Demócrata Feminista, pero sin dejar de traslucir lo que siguen siendo paradojas discursivas en ese afianzamiento de las mujeres en política. Ante la misma pregunta sobre la influencia del voto de la mujer en la política, expresaba: "Es preciso que la mujer llegue al parlamento para hacer sentir su voz en defensa de los derechos de la mujer y del niño y para obtener la equidad económica" (INFLUIRÁ..., 1938, p. 8) - lugares comunes en materia de temas que debían ser defendidos por la mujer. La diferencia entre Álvarez y García Lagos es que aquí se presenta una mujer como sujeto político, o sea, que interviene activamente desde el parlamento, aunque paradójicamente sobre temas correspondientes a los que ya se reservaban para las mujeres. Las mujeres se transformaban, así, en defensoras de los más débiles. Para lograr esto, según Álvarez, "es necesario que la mujer que llegue al Parlamento no sea representante de ningún partido político, donde los hombres puedan imponerle normas de conducta, sino que debe ser representante de las mujeres y vocero de sus necesidades económicas y sociales" (INFLUIRÁ..., 1938, p. 8). Los partidos políticos dirigidos por hombres impondrían pautas que mantendrían a las mujeres en un rol secundario. De ahí el argumento de presentarse por separado de los hombres. La paradoja la encontramos en que se pretende la igualdad de derechos entre os sexos, pero con las mujeres posicionándose desde la diferencia. Las mujeres eran diferentes a los hombres en tanto estos impondrían su autoridad a ellas, quedándolas eclipsadas en los partidos.

Paulina Luisi ${ }^{12}$ también caía en contradicciones. Consultada por la misma revista, Luisi deja en claro su postura respecto a varios escenarios que se podían presentar tomando en cuenta el contexto político que se daba en $1938^{13}$ : “en la situación política actual, sería mejor

\footnotetext{
${ }^{12}$ Médica y política uruguaya. Fue la primera doctora en Medicina egresada de la Universidad de la República. Adherente al Partido Socialista fue integrante de varios colectivos relacionados con la lucha por los derechos políticos de las mujeres en el Uruguay.

${ }^{13}$ La situación política de 1938 se manifestaba por demás compleja. El terrismo (sector gobernante dentro del Partido Colorado) se enfrentaba a una división que era producto de las candidaturas de Alfredo Baldomir y Eduardo Blanco Acevedo. A su vez, la abstención de varios sectores políticos hizo que el acto electoral se tiñera de múltiples críticas en torno a su legalidad. El batllismo (Partido Colorado), el Partido Nacional Independiente y el Partido Comunista habían resuelto la abstención para no legitimar a un gobierno que consideraban ilegal, dado el golpe de Estado de 1933. Para ampliar el tema, ver Frega, Maronna y Trochón (1987, p. 17 a 23), Oddone (1990, p. 173 a 177) y Gran derrota... (1938, p. 5).
} 
que la mujer NO VOTASE porque por ser la primera vez que ha de hacerlo, cada partido le echará irremediablemente la culpa de todo lo que vaya mal” (INFLUIRÁ..., 1938, p. 8, grifo do autor). Una de las principales referentes del feminismo uruguayo estaba proponiendo la abstención electoral de las mujeres. La paradoja aparece en tanto Luisi no quiere que las mujeres voten, siendo ella una de las pioneras del feminismo sufragista uruguayo. Las circunstancias políticas no generaban las garantías necesarias para que el voto de las mujeres se diera libremente, y incluso la propia Paulina se manifestó contraria al régimen de Terra ${ }^{14}$. Luisi (INFLUIRÁ..., 1938, p. 8) agregaba que "votando los partidos donde los hombres hacen lo que les mandan, las mujeres, que siguen el camino de esos hombres no serán más que ovejas del mismo rebaño y sus votos, gregarios como todos los demás”. En este caso no aparece ninguna esperanza de autocrítica por parte de las mujeres ni de reflexión propia en tanto ciudadanas. Luisi consideraba que las mujeres actuarían como los hombres y por tanto su voto no tenía sentido. Las mujeres seguían siendo sumisas y dominadas. Al culminar su comentario, critica la existencia del Partido Independiente Democrático Feminista, que haría su primera y única aparición electoral en estas elecciones:

[...] no concibo los partidos donde se agrupan solamente las mujeres. Para mí, la Nación es la extensión de la familia y yo no he visto ninguna familia que tenga los hombres por un lado y las mujeres por el otro. Eso está bien en las figuras del pericón, pero no en el campo político. Por eso creo que, el voto de la mujer no tendrá ahora influencia en la política del país. (INFLUIRÁ..., 1938, p. 8).

La resistencia a un partido integrado exclusivamente por mujeres no era nueva ${ }^{15}$. La paradoja de Luisi radica en que si las mujeres no podían votar con los hombres por caer en la sumisión a la cual eran sometidas, qué camino les quedaba en términos políticos? Existe una contradicción en la medida en que Luisi piensa que participando de la política, la mujer no solo mantendrá su rol secundario y sumiso frente al mandato masculino, sino que también

\footnotetext{
${ }^{14}$ La historiadora Sara López (2013, p. 58-59) hace referencia a la actividad política de Paulina en los años treinta: "En [...] 1938, las elecciones convocadas por Terra fueron impugnadas por los sectores democráticos. Paulina, desde el movimiento abstencionista le pidió a las mujeres que no votaran, dado que el país estaba bajo una dictadura y podían ser manejadas por los sectores que apoyaron al régimen." También se puede consultar Sapriza (1988, p. 100-101).

${ }^{15} \mathrm{Si}$ bien al principio la aparición de un partido político compuesto por mujeres no resultó criticado, cuando comenzó sus discusiones en torno al programa y las candidaturas de sus representantes el sistema político reaccionó en su contra. Para ampliar esta discusión, pueden ser consultados varios artículos de prensa, como Batllista enmascarado (1932, p. 3) y Nadie... (1932, p. 3). También puede ser consultado Lavrin (2005, p. 438439).
} 
romperá sus vínculos familiares porque un partido era una familia y ambos funcionaban con hombres y mujeres ${ }^{16}$.

\section{LAS PARADOJAS MÁS ALLÁ DE POSTURAS HISTORIOGRÁFICAS}

Más allá de estos planteos contradictorios, no se ha aún propuesto una discusión historiográfica acerca de la conquista o de la concesión del voto femenino. Varios trabajos que han incurrido en este interesante análisis intentan explicar desde dos ángulos la evolución de la aprobación de los derechos políticos de las mujeres en el Uruguay. El trabajo pionero de las historiadoras Graciela Sapriza y Silvia Rodríguez Villamil, si bien no niega trascendencia a los reclamos y luchas realizadas por los movimientos feministas, expresa que fueron los partidos políticos, de acuerdo con sus necesidades electorales y con determinados contextos económicos y sociales, los que concedieron el derecho al voto de las mujeres. Afirman estas investigadoras que

[...] sin perjuicio de reconocer la existencia de un movimiento feminista activo [...] nos inclinamos a pensar que la mujer ha sido escasamente "sujeto" y sí más bien "objeto" de todo este proceso. Si bien el movimiento feminista alcanzó en su momento cierta relevancia en la movilización político-social, no es posible asumir que su acción haya sido decisiva. (SAPRIZA; VILLAMIL, 1984, p. 4).

La otra mirada que surge en torno al análisis del movimiento feminista y sus logros es la de la historiadora Laura Osta. En su trabajo, Osta (2008, p. 17) expresa la tesis de que "[...] la mujer, en la lucha por el sufragio ha sido más sujeto que objeto. O sea, que ha tenido un rol, si bien no único, pero sí determinante en esta batalla". Si bien no se deja de lado la influencia que tuvieron los partidos, la idea central de su investigación es que las mujeres fueron logrando derechos por sus propios medios, construyendo un conjunto de discursos y acciones que las hicieron protagonistas de los cambios que ocurrían.

Los dos trabajos antagónicos llegan a una conclusión común: que más allá de los alcances del movimiento feminista y de los roles que ocuparon los partidos políticos en el otorgamiento de los derechos políticos femeninos, la participación de las mujeres en este proceso fue y sigue siendo escasa. Sapriza y Rodríguez Villamil (1984, p. 28) expresan que "si bien no se ha investigado la participación femenina a nivel de militancia en los partidos

\footnotetext{
16 Una explicación similar había dado en 1932 la hermana de Paulina, la doctora Clotilde Luisi, también luchadora feminista: "Las mujeres no deben agruparse para constituir un partido exclusivamente femenino. [...] Sería colocarse nuevamente en la posición de grupo apartado, que acabaría fatalmente por venir a la posición de subordinado y dirigido por los grupos masculinos.” (LAS MUJERES..., 1932, p. 5).
} 
políticos, podemos afirmar que su representación tanto en organismos legislativos como ejecutivos ha sido muy escasa." A respecto de la cuestión, Osta (2008, p. 136) expresa que "un aspecto a tener en cuenta en el futuro, es la escasa participación femenina en el gobierno."

El planteo aquí realizado sobre las paradojas intenta aplicar una técnica de análisis a los discursos de algunas mujeres en Uruguay. Analizando sus discursos y argumentos llegamos a observar limitaciones en su trascendencia tras la puesta en práctica de los derechos políticos - que terminaron siendo una realidad, plasmándose en una ley que consagraba el derecho al voto de todas las mujeres mayores de 18 años y en la Constitución de 1934 que establecía formalmente la ampliación del concepto de "ciudadanía". Esas disposiciones legales se materializaron en las elecciones de 1938. Sin embargo, más allá de los seis años que separaron la aprobación de la ley de derechos políticos y la aplicación electoral de estos, las mujeres cayeron en contradicciones discursivas y planteos teóricos que debilitaron su participación activa en los partidos y en la política. Esas limitaciones estuvieron caracterizadas por las paradojas, es decir, las contradicciones en que cayeron las mujeres a la hora de justificar su rol político y el alcance que su nuevo derecho podía tener en la vida política del país. Los hombres, como constructores de un discurso que parecía universalista, pero que no incluía a todos, también cayeron en las paradojas argumentativas. En el caso de los hombres la paradoja es más entendible, puesto que la usaron como recurso para mantener sus espacios de poder - las mujeres eran objetos políticos, pero no sujetos, puesto que de lo contrario deberían compartir los espacios de poder tradicionalmente masculinos. Las paradojas de muchas mujeres crearon un discurso que debilitó la participación femenina el na política y facilitó a los hombres el mantenimiento de una cultura de dominación masculina. Esa cultura mantenía a las mujeres en el hogar y limitaba sus acciones a temas vinculados a la familia y al cuidado de los hijos, a la vez que la hacía poco capaz de afrontar los deberes de la política activa. Es decir que desvaloriza las capacidades y aportes que las mujeres podían hacer desde el ejercicio del poder.

La escasa participación de las mujeres como sujetos en la política no fue solo una creación universalista paradójica de los hombres, puesto que las mujeres debilitaron sus argumentos a favor de su participación política con discursos que partían de las diferencias para justificar la igualdad. De esta manera se consolidaban simbólicamente los espacios de dominación que seguían siendo monopolio de los hombres. 


\section{CONCLUSIONES}

Aplicar la herramienta de las paradojas o contradicciones discursivas como análisis nos muestra los distintos significados que las intenciones planteadas pueden tener. Ubicados en una época puntual y construidos por determinadas personas, los discursos muestran los objetivos de aquellos que los declaran, que pueden se extender o consolidar determinadas relaciones de género, jerarquías sociales y definiciones políticas. En el caso de los derechos políticos, estos se pusieron en discusión en una época contestataria, como fue el siglo XVIII. Sin embargo, los argumentos ofrecidos por muchos de sus promotores consolidaron los viejos preceptos de dominio y jerarquizaciones existentes. En el caso de las mujeres, estas siguieron manteniendo ese rol secundario y sumiso respecto a los hombres.

La evolución de los discursos posteriores continuó sustentándose en esas diversas interpretaciones, que, se por un lado defendían la igualdad, por otro establecían las limitaciones que las mujeres tenían, definiéndolas por su alteridad y, así, como objetos de dominación político-social.

Las mujeres militantes de los movimientos feministas defendieron esa igualdad y, por tanto, la su aceptación como sujetos de derechos. Sin embargo, sus argumentos fueron contradictorios, debilitando el empoderamiento que el debate sobre los derechos políticos les otorgaba. Por eso, la participación política de las mujeres fue escasa en términos efectivos en el periodo estudiado. Las mujeres lograron el derecho al voto, pero siguieron ocupando roles secundarios en términos políticos y manteniendo el rol de esposa-madre, objetos de dominio masculino. La mujer no es un sujeto participante, sino un sujeto ausente. Sujeto porque se las nombran y se las dan funciones, pero sigue siendo ausente en la medida que no hacen efectiva su participación directa en las decisiones políticas, manteniendo sus funciones tradicionales.

\section{REFERÊNCIAS}

A 90 AÑOS del primer voto de la mujer en Sudamérica. El País, Montevideo. Disponível em: <http://www.elpais.com.uy/informacion/aniversario-primer-voto-mujer-sudamerica.html>. Acesso em: 6 jul. 2017.

BATLLISTA enmascarado. El Debate, Montevideo, 20 dic. 1932.

BRUERA, S.; GONZÁLEZ, M. Guía de participación política con enfoque de género. Montevideo: Oficina de Planeamiento y Presupuesto, 2011. 
CAMPS, V. El nombre del individualismo. In: MILL, J. S.; MILL, H. T. Ensayos sobre la igualdad de los sexos. Madrid: Machado Libros, 2000.

DERRIDA, J. De la gramatología. México: Editorial Siglo XXI, 1986.

FOUCAULT, M. La arqueología del saber. México: Editorial Siglo XXI, 2007.

FREGA, A.; MARONNA, M.; TROCHÓN, Y. Baldomir y la restauración democrática. Montevideo: Ediciones de la Banda Oriental, 1987.

GRAN DERROTA sufrieron en las urnas las tendencias extremistas. El Pueblo, 4 abr. 1938.

HUNT, L. La invención de los derechos humanos. Barcelona: Tusquets Editores, 2009.

LA IMPRESIÓN que tuvieron al votar por primera vez. Mundo Uruguayo, Montevideo, 7 abr. 1938.

¿INFLUIRÁ el voto de la mujer en la política del país? Mundo Uruguayo, Montevideo, 17 mar. 1938.

JOHNSON, N. et al. Renovación, paridad: horizontes aún lejanos para la representación política de las mujeres en las elecciones uruguayas 2014. Montevideo: Cotidiano Mujer, 2015. Disponível em: <http://cotidianomujer.org.uy/sitio/pdf/pub_politicas15.pdf>. Acesso em: 5 jul. 2017.

LAVRIN, A. Mujeres, feminismo y cambio social en Argentina, Chile y Uruguay. Santiago de Chile: Centro de Investigaciones Diego Barcos Arana, 2005.

LÓPEZ, S. El legado de las hermanas Luisi, cien años después. Montevideo: UDELAR, 2013.

LA MUJER uruguaya. El Pueblo, Montevideo, 17 mar. 1938.

LAS MUJERES no deben agruparse para constituir un partido exclusivamente feminista. $E l$ Pueblo, Montevideo, 30 dic. 1932.

NADIE puede predecir qué porvenir tendrá en el Uruguay el partido feminista. El Pueblo, Montevideo, 27 dic. 1932.

ODDONE, J. Uruguay entre la depresión y la guerra 1929-1945. Montevideo: Fundación de Cultura Universitaria, 1990.

OSTA, M. L. El sufragio: Una conquista femenina. Montevideo: Obsur, 2008.

PARADOJA. In: DICCIONARIO de la Real Academia Española. Disponível em: $<$ http://dle.rae.es/?id=Rplrgi1 >. Acesso em: 3 jul. 2017.

PATRIÓTICAMENTE votará la mujer. El Pueblo, Montevideo, 22 mar. 1938. 
POR PRIMERA vez votarán las mujeres el 27 de marzo. El Pueblo, Montevideo, 2 mar. 1938.

SAPRIZA, G.; VILLAMIL, S. R. El voto femenino en el Uruguay: ¿conquista o concesión? Montevideo: GRECMU, 1984. Serie Documentos ocasionales, n. 2.

SAPRIZA, G. Memorias de rebeldía: siete historias de vida. Montevideo: Puntosur, 1988.

SCOTT, J. W. Las mujeres y los derechos del hombre: Feminismo y sufragio en Francia 1789-1944. Buenos Aires: Editorial Siglo XXI, 2012a.

Parité! Equidad de género y la crisis del universalismo francés. México: Fondo de Cultura Económica, 2012b.

URUGUAY. Ley n ${ }^{\circ}$ 18.476, de 21 de abril de 2009. Registro Nacional de Leyes y Decretos. Disponível em: $<$ https://parlamento.gub.uy/documentosyleyes/leyes?Ly_Nro=18476\&Ly_fechaDePromulgac ion $\% 5 \mathrm{Bmin} \% 5 \mathrm{D} \% 5 \mathrm{Bdate} \% 5 \mathrm{D}=\& \mathrm{Ly} \_$fechaDePromulgacion $\% 5 \mathrm{Bmax} \% 5 \mathrm{D} \% 5 \mathrm{Bdate} \% 5 \mathrm{D}=\&$ Ltemas $=\&$ tipoBusqueda $=T \&$ Searchtext=>. Acesso em: 5 jul. 2017. 